\title{
Severe Pre-Eclampsia and Eclampsia in the Service of Obstetrics and Gynecology of Regional Teaching Hospital of Ouahigouya (RTHO): Clinical, Therapeutic and Evolutive Aspects
}

\author{
Ouedraogo Issa ${ }^{1}$, Sawadogo Yobi Alexis ${ }^{1}$, Sib Sansan Rodrigue ${ }^{2}$, Kain Paul Dantola ${ }^{1}$, \\ Zamané Hyacinthe ${ }^{1}$, Kiemtoré Sibraogo ${ }^{1}$, Ouattara Adama ${ }^{1}$, Sanogo Moussa ${ }^{3}$, \\ Abdou Aboubacary ${ }^{3}$, Kaboré Sidbéwenné Yacinthe ${ }^{4}$, Ouedraogo Ali ${ }^{1}$, Bonané-Thieba Blandine ${ }^{1}$ \\ ${ }^{1}$ Department of Obstetrics and Gynecology, Ouaga I University Pr Joseph Ki Zerbo, Ouagadougou, Burkina Faso \\ ${ }^{2}$ Department of Obstetrics and Gynecology, Ouahigouya University, Ouahigouya, Burkina Faso \\ ${ }^{3}$ Regional Teaching Hospital of Ouahigouya, Ouahigouya, Burkina Faso \\ ${ }^{4}$ Regional Center Hospital of Tenkodogo, Tenkodogo, Burkina Faso \\ Email address: \\ oued_issa2002@yahoo.fr (O. Issa)
}

\section{To cite this article:}

Ouedraogo Issa, Sawadogo Yobi Alexis, Sib Sansan Rodrigue, Kain Paul Dantola, Zamané Hyacinthe, Kiemtoré Sibraogo, Ouattara Adama, Sanogo Moussa, Abdou Aboubacary, Kaboré Sidbéwenné Yacinthe, Ouedraogo Ali, Bonané-Thieba Blandine. Severe Pre-Eclampsia and Eclampsia in the Service of Obstetrics and Gynecology of Regional Teaching Hospital of Ouahigouya (RTHO): Clinical, Therapeutic and Evolutive Aspects. Journal of Gynecology and Obstetrics. Vol. 6, No. 1, 2018, pp. 6-10. doi: 10.11648/j.jgo.20180601.12

Received: January 21, 2018; Accepted: February 1, 2018; Published: March 6, 2018

\begin{abstract}
We present a study to the clinical, therapeutic and evolutive aspects of severe pre-eclampsia and eclampsia in the service of obstetrics and gynaecology of regional teaching hospital of Ouahigouya. We have conducted a descriptive and analytical study with retrospective data collection within 3 years, from $1^{\text {st }}$ January 2013 to $31^{\text {st }}$ December 2015 . We have recorded 5791 deliveries out of which 261 were included giving a rate of $4.51 \%$ (61 cases of eclampsia $1.05 \%, 200$ cases of severe pre-eclampsia, 3.45\%). The most affected patients were the women with age ranging between $16-20$ years $(33.3 \%)$, the nulliparous women $(24.2 \%)$, the multiparous women $(25.5 \%)$, married women $(84 \%)$ and those without renumbering activity $(86.6 \%)$. Maternal prognosis was dominated by a morbidity linked to fever $(24.8 \%)$, coma $(21.7 \%)$ and acute kidney failure (14.9\%). Maternal lethality rate was $1.92 \%$ and the fetal mortality was $24.6 \%$.
\end{abstract}

Keywords: Pre-Eclampsia, Eclampsia, Clinical, Management, Prognosis

\section{Introduction}

Hypertension disorders during pregnancy, particularly severe pre-eclampsia and eclampsia affect about $8 \%$ of pregnancies and lead to $12 \%$ of maternal death in the whole world [1]. In developed countries, the incidence of severe pre-eclampsia and eclampsia is low (0.5 to $2 \%)$ and its prognosis has been improved due to the improvement of obstetrics, resuscitation and neonatology [2].

Eclampsia is one of serious complications of hypertension crisis during pregnancy [3]. Eclampsia leads to maternal deaths 50000 per year in the world. In Africa, eclampsia affects one pregnancy out of 2000 with maternal death of $30 \%$ and fetal and perinatal mortality of $20 \%$ [1], [4].

In Burkina Faso, the maternal lethality rate linked to eclampsia was 3, 3\% at University Hospital Yalgado Ouedraogo (UHCYO) and eclampsia was the fourth maternal death cause behind hemorrhages, infections and complications of abortion [5].

In the service of obstetrics and gynecology of regional teaching hospital of Ouahigouya (RTHO), there is updating on the use of magnesium sulfate for the management of eclampsia with a protocol of use and the magnesium sulfate is always available. Despite that, the materno-fetal mortality linked to severe pre-eclampsia and eclampsia remains high in 
the service. Yet, all authors agree that a rapid diagnosis followed by a right management may improve the prognosis of these pathologies.

Even if the lethality of pre-eclampsia has become low, it remains high despite multiples efforts against that disease.

However, few studies have been performed on severe preeclampsia and eclampsia in the service of obstetrics and gynaecology of regional teaching hospital of Ouahigouya (RTHO). It has appeared to us a necessity to conduct a concomitant study (severe pre-eclampsia and eclampsia) in the goal to compare the frequencies of these pathologies, epidemiological profile of patients but also to assess the quality of management of these pathologies.

\section{Patients and Methods}

The study has been performed in the service of obstetrics and gynaecology of regional teaching hospital of Ouahigouya (RTHO).

The RTHO is the referral center of six sanitary districts of the North Region which are: Ouahigouya, Titao, Thiou, Seguenega, Gourcy and Yako. Its population zone of cover is estimated of 1306619 inhabitants. We conducted a crosssectional study for descriptive and analytical purposes including a retrospective data collection during a period of 3 years, from 1st January 2013 to 31st December 2015.

The study was based on pregnant women, parturient women and delivered women hospitalized at the maternity of RTHO during the study period on account of either severe pre-eclampsia or eclampsia.

Were included in the study, any patient who had:

1. Diastolic blood pressure $\geq 110 \mathrm{mmHg}$ beyond 20 weeks of gestation associated with a positive proteinuria higher than three crosses.

2. Or a total seizures often added to the criteria of diagnosis of pre-eclampsia (diastolic blood pressure higher than or equal to $90 \mathrm{mmHg}$ beyond 20 weeks of gestation with positive proteinuria at least two crosses)

We're not included in the study, the patients with pregnancy aged less or equal to 20 weeks of gestation or not sure or patient whom folder were not infeasible.

Variables used were:

- socio-demographical characteristic (age, parity, occupation, marital status and origin)

- clinical characteristic (mode of admission, monitoring of pregnancy, physical and functional signs)

- The data from the supplementary examinations (albuminria, blood count, creatininemia, AST/ALT, Background eye, ECG).

- The data linked to the management, maternal and fetal prognosis as well

Using a pretested questionnary, the data were collected using patients folders, theatre book, delivery and hospitalization book of the maternity.

The data collected were recorded and analyzed by using Word, Microsoft and Excel 2010 software, and Epi-info 7.1.4.0 version. The results have been presented on percentage form for qualitative variables and means form and standard deviation for quantitative variables.

\section{Results}

\subsection{Frequency of Pre-Eclampsia and Eclampsia}

A total of 261 cases of pre-eclampsia and eclampsia were collected from 5791 deliveries, a frequency of $4.5 \%$, including 61 cases (1\%) of eclampsia and 200 cases (3.5\%) of pre-eclampsia. severe

\subsection{Socio-Demographical Characteristic}

The mean age of patient was $25.71 \pm 5$ years with a range of 15 and 41 years; $33.3 \%$ of patient were between 16 and 20 years old. The mean parity was $2 \pm 2$. The biggest parity was 11 and the primiparous women represented $51 \%$. The women without renumbering activities (housewives and pupils) represented $86.6 \%$ and $92.3 \%$ had marital live (married or cohabiting).

\subsection{Clinical Aspects}

The referred patient represented $80.1 \%$. The main reasons of evacuation were hypertension $(61.8 \%)$, seizures $(15.8 \%)$ and abdomino-pelvic pain (3.3\%).

Functional signs at admission were headaches (51\%), dizziness $(38.3 \%)$, and seizures $(10 \%)$.

The mean age of occurring of the pathology during the pregnancy was 34.5 weeks of gestation with a range of 22 and 44 weeks of gestational age. In the post-partum, the mean delay of occurring of eclampsia crisis was 4.13 days with a range of 0 and 16 days.

The pathology (Pre-eclampsia and eclampsia) has occurred in antepartum in $46.4 \%$ as shows in table 1 .

Table 1. Distribution of patients according to the diagnosis period of the Severe eclampsia and eclampsia.

\begin{tabular}{lll}
\hline Diagnosis period of severe preeclampsia/eclampsia & Number & \% \\
\hline Antepartum & 121 & 46,4 \\
Intrapartum & 96 & 36,8 \\
Postpartum & 44 & 16,8 \\
Total & 261 & 100 \\
\hline
\end{tabular}

The mean diastolic blood pressure at admission was 110.8 $\mathrm{mmHg}$ with a range of 80 and 160 , and $62 \%$ of patients had a positive album, inuria higher than two crosses.

On biological side, on noted anemia and thrombopenia respectively in $30.1 \%$ and $20.5 \%$ of cases and hyper creatininaemia in $34 \%$ of cases as it shows in table 2 .

Table 2. Distribution of patients according to the results of Biology $(n=$ 259).

\begin{tabular}{lll}
\hline Characteristics & Number & \% \\
\hline Hemoglobin level $(\mathrm{g} / \mathrm{dl})$ & & \\
$<6$ & 5 & 1,9 \\
{$[6,11]$} & 73 & 28,2 \\
$\geq 11$ & 181 & 69,9 \\
Pads $(/ \mathrm{mm} 3)$ & & \\
$<150000$ & 53 & 20,5 \\
\hline
\end{tabular}




\begin{tabular}{lll}
\hline Characteristics & Number & \% \\
\hline$[150000,400000]$ & 197 & 76 \\
$>400000$ & 09 & 03,5 \\
Creatinine $(\mu \mathrm{mol} / 1)$ & & \\
$<90$ & 171 & 66 \\
$\geq 90$ & 88 & 34 \\
\hline
\end{tabular}

Hepatic function was disrupted in $19.7 \%$ of cases (table 3 )

Table 3. Patient Distribution Based on ASAT / ALT rate.

\begin{tabular}{lll}
\hline Variables & Number & \% \\
\hline ASAT $(\mathrm{n}=71)$ & & \\
Normal & 57 & 80.3 \\
High & 14 & 19.7 \\
ALAT $(\mathrm{n}=71)$ & & \\
Normal & 58 & 81.7 \\
High & 13 & 18.3 \\
\hline
\end{tabular}

\subsection{Therapeutic Aspects}

A treatment against seizures was administrated to our patients based on magnesium sulfate in $86.6 \%$ (226/261) and diazepam in $13.4 \%$ of cases. An anti-hypertensive treatment had been done with clonidin in $99.6 \%$ (260/261) whom associated with amlopdipin in 41.2\% (107 patients).

Obstetrical management had been by vaginal delivery in $52.9 \%(99 / 187)$ of cases.

\subsection{Prognosis Aspects}

\section{- Maternal prognosis}

Maternal morbidity was marked by infections in $48.6 \%$, coma $(33.3 \%)$ and hemodynamic disorders $(21.9 \%)$ as it shows in table 4.

Table 4. Distribution of patients according to maternal complications ( $n=$ 105).

\begin{tabular}{lll}
\hline Maternal Complications & Number & \% \\
\hline State of eclamptic & 02 & 01.9 \\
Retroplacental Hematoma & 07 & 06.7 \\
Acute Renal Insufficiency & 09 & 08.6 \\
Ascites & 03 & 02.9 \\
Haemorrhage from delivery & 03 & 02,9 \\
Infections & 51 & 48.6 \\
Hemodynamic complications & 23 & 22.0 \\
Vascular complication & 07 & 06.5 \\
Coma & 35 & 33.3 \\
HELLP syndrome & 02 & 01.9 \\
\hline
\end{tabular}

A total of five maternal deaths were recorded, a fatality rate of $1.92 \%$. The causes of these deaths were one case of coagulopathy disorders, one of eclamptic evil state and three cases of severe sepsis.

- Fetal prognosis

The main neonatal morbidities were prematurity $(32.1 \%)$, neonatal infections (15\%) and fetal distress (11.2). A total of 46 stillbirths were recorded among 187 neonates, a perinatal death rate of 246 per 1000 newborns

- Prognosis factors

Chi square test (X2) was used to evaluate poor prognostic factors. It says that from our analysis that prematurity and vaginal deliveries increase the risk of stillborn respectively in
$39.4 \%$ and $38.4 \%$ of cases, $p$ value equal to 0.0006 and 0.000000006 as it shows in tables 5 and 6 .

Table 5. The status of the fetus according to the mode of delivery.

\begin{tabular}{llll}
\hline Mode of delivery & Stillbirth & Born alive & Total \\
\hline Cesarean section & 08 & 80 & 88 \\
Delivery natural way & 38 & 61 & 99 \\
Total & 46 & 141 & 187 \\
\hline
\end{tabular}

The critical value is 0.004 at the $5 \%$ threshold and 1 degree of freedom. $\mathrm{X}^{2}=$ 0.60 and $\mathrm{P}=0.0006 . \mathrm{X}^{2}>0.004$ and $\mathrm{P}<5 \%$. Therefore the mode of delivery has an impact on the vitality of the fetus.

Table 6. The status of the fetus according to the term of the pregnancy.

\begin{tabular}{llll}
\hline Term (Week of Amenorrhea) & Stillborn & Born alive & Total \\
\hline$<37$ & 43 & 66 & 109 \\
$\geq 37$ & 03 & 75 & 78 \\
Total & 46 & 141 & 187 \\
\hline
\end{tabular}

$\mathrm{X}^{2}=1.54 . \mathrm{P}=0.000000006 . \mathrm{X}^{2}>0.004$ and $\mathrm{P}<5 \%$. This means that the term of pregnancy has an impact on the vitality of the fetus at birth.

\section{Discussion}

\subsection{Limitations and Biases}

The retrospective feature of data collection has been origin of limitation by:

1. Lack of computerized archives service of files

2. Loss of some of clinical folders

3. Insufficiency of information in some of clinical folders ( no report of some important items or lack of record of biological examinations information's)

Despite of these limitations, we have reached to these results that we have compared to literature data.

\subsection{Frequency}

Our frequency was $4.5 \%$ whom $1 \%$ of eclampsia and 3.5 of severe pre-eclampsia.

Pre-eclampsia occurs in about 5 to $10 \%$ of pregnancies according to the literature [6], [7], [8] and the prevalence of severe pre-eclampsia is estimated diversely according to the criteria of definition, to populations studied and its heterogeneity.

The frequency of severe pre-eclampsia in our study $(3.5 \%)$ is close to those found by Tchaou B. A. [9] Benin and Hodonou F. [10] in Burkina Faso who reported respectively $4.7 \%$ and $4.1 \%$. On the other hand, it was so higher than those reported by Cisse C. T [11] in Senegal and Girad B. [8] in France who found respectively $1.4 \%$ and $1.25 \%$.

The rate found in the study is significantly lower than those found by Mayi-songa S. [12] in Gabon who has reported a rate of $7.5 \%$.

Eclampsia has become a rare complication in developed countries by precocity of management in front of main signs of pre-eclampsia. On the other hand, the monitoring of pregnancy by a qualified medical staff, the screenings of risk pregnancies and information's patients have helped to decrease that pathology [13].

Nonetheless, it remains present in our in-low resources 
countries (1\% in our study) and that prevalence is almost regular in sub-Saharan Africa [4], [14], [15].

It is higher than those found by Ozumbia B. C. in Nigeria [16], Simazue A. in Gabon [17] and MWINYOGLEE J. in South Africa [18] which was respectively $0.2 \%, 0.27 \%$ and $0.4 \%$. That high rate is linked to lost factors which have low socio-economic level of populations as common factor. In the study, the major worry was the faulty management of hypertension crisis link to bad monitoring during antenatal visit which does not allow detecting early high blood pressure.

\subsection{Mode of Delivery}

In the study, 69 patients, $37.7 \%$ have delivered by cesarean section.

Our result is similar to those found by Lankoande J. [19] in Ouagadougou, Tchaou B. A. [9] in Benin, and Cisse C. T. [11] in Senegal with respectively $45.7,41.7 \%$ and $50 \%$.

Cesarean section rates higher than ours have been reported by Cisse C. T. in Senegal [11] and Mayi-tsonga S. in Gabon [12]. They have reported respectively $64.1 \%$ and $74 \%$ of cesarean section rate in their studies. In our study, the low cesarean section rate may be explained that in the regional teaching hospital of Ouahigouya (RTHO), there is an insufficiency of staff because the same team in charge of general surgery theatre and that of maternity; also cesarean indication is for the pregnant women whom delivery is not impending within 24 hours (according to WHO protocol).

\subsection{Therapeutic Data}

The management by drugs is based on administration of ant-hypertensive medicine, magnesium sulfate according to WHO, as it was the case in this study for the treatment and prevention of seizures.

Treatment using Clonidin was instituted in $99.6 \%$ of patients. Neji K. and Brouth Y. [20], [21] have used Dihydralazin in more than the half of their patients. Diouf A. A. [22] has used Nicardipin in $88 \%$ of cases. Even if the comparison between the types of anti-hypertensive drugs did not get un advantage for any of type [23], the use of central antihypertensive drugs in our study can explain by its effectiveness, safety, cheapness and mostly the unavailability in our settings of Dihydralazin as recommended by WHO in first line.

Magnesium sulfate was used in $86.6 \%$ of cases. Our results are lower than those of Diouf A. A. in Senegal which was $100 \%$ [22]. In the other hand, Tchaou B. A. [9] in Benin has reported a using rate of $57.2 \%$ in their study based on severe pre-eclampsia. Mayi-tsonga S. in Gabon [12] has found a using rate of $42.7 \%$ in severe pre-eclampsia patients and Cisse C. T. [3] has reported a rate of $53 \%$ in eclampsia patients.

The high use rate of magnesium sulfate is linked to that it is used in first intention according to WHO protocol and it is available in our service.

\subsection{Materno-Fetal Prognosis}

\section{- Maternal prognosis}

In this study, we have recorded 5 maternal deaths with a lethality rate of $1.92 \%$. That rate is close to that of Diouf A. A. [22] in Senegal who has found $1.62 \%$. But it is clearly lower than those reported by Cisse C. T. [3] in Senegal (17.9\%) for eclampsia, Bambara M. [14] in Burkina Faso $(7.14 \%)$ for eclampsia, Tchoua B. A. in Benin [9] who found $6.8 \%$ of complications of severe pre-eclampsia.

That may explain by the improvement of management of that pathology by medical staff. The causes of these deaths were: one case of hemorrhage, two cases of hypovolemic shock after cesarean and two septic shocks. $t$

- Fetal prognosis

In the study, perinatal mortality was estimated to $24.6 \%$. That rate is similar to those found by Simazue A. in Gabon [17], Baeta S. in Togo [24] which was respectively $26.6 \%$ and $28.6 \%$ for eclampsia. However, it is higher than those found by Cisse C. T. in Senegal [3], Faye A. [25] and Mayitsonga [12] in Gabon, respectively $3.6 \%, 13.2 \%$ and $12.2 \%$.

Our high rate may explain by the late of maternal management, the insufficiency of adequate buildings and means of neonatal resuscitation.

- Factors prognosis

Prematurity and vaginal delivery has contributed to increase the frequency of stillbirth in pre-eclampsia and eclampsia. Prematurity would be induced by severe preeclampsia and eclampsia. To others authors [26], 60\% of perinatal deaths and $50 \%$ of neurologic sequels due to delivery before 32 weeks of gestational age.

The use of cesarean section has become common in the service in case of pre-severe pre-eclampsia or eclampsia. When cesarean section has performed with optimal precautions, it contributes to improve the maternal and fetal prognosis.

\section{Conclusion}

Severe pre-eclampsia and eclampsia remain pregnant women dreadful pathology seeing its complications leading to threat either maternal or fetal prognosis. Despite lots efforts of national and international health partnerships which have contributed to vulgarize reentered antenatal care monitoring and the subvention of obstetrical and neonatal emergencies cares by Burkina state, the incidence of these pathologies remains relatively increases in our country. Nevertheless, these strategies have contributed to improve the management of these pathologies which has helped to reduce the maternal death rate linked to severe pre-eclampsia and eclampsia. On the other hand, a high maternal morbidity and perinatal death are implanted to these pathologies.

\section{Competing Interests}

The authors declare that they have no competing interests. 


\section{Ethics Approval \& Consent to Participate}

This study was conducted under the supervision of THE UNIVERSITY OUAGA I PROFESSOR JOSEPH ZERBO KY, medical school. We obtained the approval of the Chief executive officer of the REGIONAL HOSPITAL of OUAHIGOUYA after approval of the Medical Establishment Commission which acts as an ethics committee at the local level.

\section{References}

[1] Gifford R. W., August P. A., Cunningham G., and al. AND Natl High Blood Pressure Educt P. Report of the National high blood pressure education program working group on high blood pressure in pregnancy. Am j. Obstet Gynecol 2000; 183: S1-S22.

[2] Collange O, Launoy A, Dietemann J, L, Pottecher T. Eclampsia. Ann Fr. Anesth Réanim. 2010; 29: 75-82.

[3] Cisse C. T, Faye Dienne M. E, Ngabo D, Mbaye M, Diagne P. M, Moreau J. C. Therapeutic and prognostic indications of eclampsia at the Dakar University Hospital. Jr Gynecology Obstetr. Biol. Reprod. 2003; 32; 3: 239-245.

[4] Thiam M., Gombaal M., GNing S., Fall P., D. Cellier, C. Perret J. Maternal and Fetal Prognosis of High Blood Pressure and Pregnancy in Sub-Saharan Africa (Senegal). J Gyn Obst Biol Reprod 2003; 32: 35-8.

[5] Ouattara A., Ouédraogo C. M. R., Ouédraogo A., Kain D. P., Zamané H., Kiemtoré S., Sawadogo Y., Millogo-Traoré F. D., Tieba-Bonané B., Lankoandé J. Soc. Pathol. Exot. (2015) 108: 316-323.

[6] Girard B., Beucher G., Muris C., Vardon D., Dreyfus M., Herlicoviez M. Magnesium sulphate and preeclampsia in routine practice: indications, safety and side effects. J. Gynécol. Obstet. Biol. Reprod. 2003; 32: 3.

[7] Firoz T., Sanghvi H., Merialdi M., Von Deleszen P. Preeclampsia in low and middle income countries. Best Pract. Res. Clin. Obstet. Gyneacol. 2011; 25 (4): 537-48.

[8] World health organization. Management of complications of pregnancy and childbirth: a guide for midwives and doctors. World Health Organization, 2004: S-52.

[9] Tchaou B. A., Salifou K., Hounkponou F. M. Management of severe preeclampsia in the University Hospital of Parakou (Benin). Book SARANF, Volume $17 \mathrm{n}^{\circ} 2-2012$.

[10] Hodonou F., Kambou T., Bazie A. J. Transfer of patients in pregnancy-puerperal state to intensive care in Burkina Faso. Gyn. Obstet. And Fertility 2003; 31: 123-12.

[11] Cisse C. T. Thiam M., Diagne P. M., Moreau J. C. Preeclampsia in Africa: epidemiology and prognosis at the Dakar University Hospital. The Letter of the Gynecologist - $\mathrm{n}^{\circ}$ 301 - April 2005 www.edimark.fr/ Letter of the Gynecologist /n_301_04-2005.
[12] Mayi-Songa S., Mimbila-Mayi M., Mandji JM, Megne Mbo M., Makoyo O., Manli D., Pither S. Maternal-fetal prognosis of severe preeclampsia in Libreville (GABON) Introduction of magnesium sulfate. Journal of the SAGO, 2011, vol 12 n2: 1418.

[13] Jamelle R. N. Eclampsia: a taxing situation in the third world. Int. J. Gynecol. Obstet., 1997; 58: 311-2.

[14] Bambara M, Rouamba A, Dao B, Yaro S, Bonkoungou P, Lankoande J, Kone B. Eclampsia in an African setting: About 56 cases at the Bobo-Dioulasso University Hospital Center Souro Sanon (UHCSS) maternity center (Burkina Faso): 2004, vol. 5, no. 2, p. 20.

[15] Beye M. D., Diouf I., Bah M., Ndoye Diop M., Kane O., Sall Ka B. Management of Hellp syndrome in intensive care in Dakar. Ann Fr Anesth Reanim. 2006; 25 (3): 291-295.

[16] Ozumbia B. C., Ibe A. I. Eclampsia in Enugu, Easterm Nigeria. Acta Obstet. Gynecol. Scand., 1993; 72: 189-92.

[17] Simazue A., Ndinga J. P., Benamar D., Ngaka Nsafu. Management of eclampsia at the Hospital Center of Libreville. Rev. Afr. Anesth. Med. Urg., 1996; 3: 14-18.

[18] Mwinyoglee J., Amako D. H., Simelela N., Marivate M. Eclampsia at Ga-Rankuwa Hospital. S. Afr. J., 1996; 86: 1539-9.

[19] Lankoande J., Toure B., Ouedraogo A., Ouedraogo C. M. R., Ouattara P., Bonane B. Kone B. Eclampsia at the maternal hospital of the Yalgado Ouédraogo National Hospital Center in Ouagadougou (Burkina Faso). Epidemiological, clinical and evolutionary aspects. Med. Afr. Black, 1998; 45: 399-402.

[20] Neji K, Boudhraa K, Baronni M, Ajroud C, Ben Ammar J, Oueslati H. and al. Management of eclampsia. J. Magh. A. Réa 2001; 3: 103-6.

[21] Brouh Y, Ndjeundo P, Tetchi Y D, Amonkou A, Yaich P. Eclampsia in university hospital in Ivory Coast: management, evolution and prognostic factors. CAN J Anesth 2008; 5: 4238.

[22] Beaufils M. Severe hypertension. Encyclical. Med. Chir Nephrology-Urology 18-058-D-10, Gynecology-Obstetrics 5036-A-10, Cardiology 11-302-K-10, 2001.

[23] Diouf AA, Diallo M, Mbaye M, Diarra SS, Faye M., Moreau $\mathrm{JC}$ and al. Epidemiological profile and management of eclampsia in Senegal: about 62 cases. Pan African Med Journal 2013; 16: 83.

[24] Baeta S., Tete K. V. S., Noutsougan Y. M., Nyame A. N., Akpadza K. S. Eclampsia at the University Hospital of Lomé (Togo): Risk factors, maternal and perinatal prognosis. Journal of SAGO, 2002, vol. 1, no. 1, 1-6.

[25] Faye A., Picaud A., Ogowet-Igumu N., Nlome-Nze R. A., Nicolas P. Eclampsia at the Hospital Center of Libreville: 53 cases for 41285 births from 1985 to 1989 . Rev. Br. Gynécol. Obstét., 1991; 86: 7-9, 503-10.

[26] Courbiere B, Carcopino X. Obstetric gynecology: national classification tests (NCT). Editions Vernazobres-Grego 20062007; 51-62. 